\title{
Effect of the PTEN gene on adhesion, invasion and metastasis of osteosarcoma cells
}

\author{
YONG HU ${ }^{1,2}$, SHENGLIN XU ${ }^{2}$, WENSEN JIN ${ }^{3}$, QIYI YI ${ }^{3}$ and WEI WEI ${ }^{1}$ \\ ${ }^{1}$ Institute of Clinical Pharmacology and Key Laboratory of Anti-inflammatory and Immunopharmacology \\ of the Education Ministry of China, Anhui Medical University, Hefei, Anhui 230032; \\ ${ }^{2}$ Department of Orthopedics, The First Affiliated Hospital of Anhui Medical University, Hefei, Anhui 230022; \\ ${ }^{3}$ Teaching and Research Section of Nuclear Medicine, Anhui Medical University, Hefei, Anhui 230032, P.R. China
}

Received April 2, 2014; Accepted July 4, 2014

DOI: $10.3892 /$ or.2014.3362

\begin{abstract}
The phosphatase and tensin homolog (PTEN) gene, an important tumor-suppressor gene, has been demonstrated to have the potential for inhibiting proliferation, migration and invasion in various types of cancer cells. The aim of the present study was to investigate the effect of PTEN expression on osteosarcoma (OS) cells. The wild-type PTEN plasmid was transfected into OS U2-OS cells. The effects of PTEN on the adhesion, migration and invasion of U2-OS cells were evaluated by cell adhesion analysis, in vitro scratch and Transwell assays, respectively. The levels of MMP-2 and MMP-9, and focal adhesion kinase (FAK) protein regulated by PTEN were detected via western blot analysis. Meanwhile, the level of intracellular FAK phosphorylation was observed. The results from the present study showed that overexpression of PTEN transcription and protein were observed in U2-OS cells following PTEN transfection. Furthermore, the migration, invasion and adhesion capabilities of the cells with PTEN transfection were significantly decreased compared to these capacities in the cells without PTEN. Meanwhile, it was shown that there was downregulation of MMP-9, FAK and p-FAK concomitant with the elevation of the intracellular PTEN level. It is therefore evident that the upregulation of PTEN may attenuate the adhesion, migration and invasion capabilities of OS cells. The mechanisms of the effects of PTEN on OS cells may be correlated with a reduction in the related genes by PTEN regulation.
\end{abstract}

\section{Introduction}

Osteosarcoma (OS) is a common primary bone tumor characterized by a very high metastatic potential $(1,2)$. Unlike

Correspondence to: Professor Wei Wei, Institute of Clinical Pharmacology and Key Laboratory of Anti-inflammatory and Immunopharmacology of the Education Ministry of China, Anhui Medical University, 81 Mei-Shan Road, Hefei, Anhui 230032, P.R. China

E-mail: aydweiw@126.com

Key words: osteosarcoma, PTEN, adhesion, migration, invasion other bone tumors, OS frequently presents in the extremities of teenagers and young adults $(3,4)$. Eighty percent of patients with OS have metastatic or micrometastatic lesions at the time of diagnosis (5). Although the prognosis of OS has improved in the past two decades with the development of modern chemotherapy and surgical resection, the mortality is still dependent on the existence of metastatic lesions rather than on the primary tumor. Therefore, a low survival rate is shown in a large number of patients due to early metastases $(1,6,7)$. To date, the mechanism of OS metastasis is still poorly understood. Therefore, it is essential to elucidate the molecular events that drive OS progression and the metastatic process in order to evaluate prognosis, to develop new diagnostic techniques, and to assess methods and effective therapy for OS.

The phosphatase and tensin homolog gene (PTEN), also named mutated in multiple advanced cancers (MMAC-1), was identified in 1997 as a tumor-suppressor gene and is located at human chromosome band 10q23. PTEN can encode a series of specificity proteins, which regulate cellular processes such as cell growth, survival, proliferation and migration (8-12). Moreover, PTEN is one of the frequently mutated genes in a wide range of human cancers, including breast, prostate, kidney and bladder carcinomas, as well as glioblastomas (13-17). It was also shown that loss of PTEN appears to be strongly associated with invasive and malignant phenotype of several types of cancers (16,18-22). Alteration of the PTEN gene causes upregulation of several downstream genes and activation of signaling pathways $(12,17,18,20,23-25)$. Expression of wild-type PTEN in different cancer cells inhibits the growth and survival of cancer cells $(18,25,26)$.

It has further been observed that PTEN has the potential to regulate the invasive behavior of tumor cells by affecting the expression and phosphorylation level of focal adhesion kinase (FAK) (27). The activation of FAK promotes the proliferation and invasion of tumor cells, which are crucial for cancer development and metastasis (28-30). In addition, FAK can increase secretion of the matrix metalloproteinases in tumor cells, including MMP-2 and MMP-9 $(30,31)$. Therefore, the levels of the above proteins are significantly involving with the capabilities of malignant tumor cell invasion and metastasis through degradation of the extracellular matrix (ECM) $(31,32)$. Since PTEN has been reported to decrease the ability of tumor 
cells to pass through the ECM by inhibiting the level of FAK, it has been postulated that functional restoration of PTEN may provide a powerful tool by which to inhibit tumor cell growth and invasion.

Some data have shown that the copy number loss in PTEN is a common events in OS cells $(33,34)$. However, little is known whether PTEN expression influences the malignant characteristics of OS cells, such as the capabilities of adhesion, migration and invasion. It also remains unclear whether PTEN regulates the expression and phosphorylation of FAK and the levels of downstream genes in OS cells.

In the present study, we observed changes in the adhesion, migration and invasion of U2-OS, a human OS cell line, by transfecting recombinant PTEN plasmid. The alteration of MMPs and FAK protein and the level of FAK dephosphorylation were investigated as well.

\section{Materials and methods}

Antibodies and reagents. Rabbit antibodies against human FAK, p-FAK, MMP-2 and MMP-9 were purchased from Bioworld Technology Inc. (USA), and the rabbit antibody against human PTEN was obtained from Beyotime Institute of Biotechnology (Jiangsu, China). The antibody against $\beta$-actin was purchased from Zhongshan Golden Bridge Biotechnology Co. (Beijing, China) and horseradish peroxidase-conjugated secondary anti-rabbit IgGs were obtained from Kangwei Biological Co. (Beijing, China). Lipofectamine 2000, serumfree Opti-MEM medium and TRIzol reagent were purchased from Invitrogen Corporation (USA). McCoy's 5A medium (powder) was purchased from Sigma-Aldrich Corporation (USA). Rat tail type I collagen was purchased form BD Biosciences (Bedford, MA, USA). Transwell chambers (8.0 $-\mu \mathrm{m}$ pore size) were obtained from Corning (Corning, NY, USA).

Cell culture and treatment. Human OS U2-OS cells were obtained from the Cell Bank, Chinese Academy of Sciences (Shanghai, China). Fetal bovine serum (FBS) and L-glutamine were purchased from Sijiqing Biological Engineering Company (Hangzhou, China). Cells were maintained in McCoy's 5A medium supplemented with $10 \%$ fetal bovine serum, $100 \mathrm{U} / \mathrm{ml}$ penicillin and $100 \mathrm{mg} / \mathrm{ml}$ streptomycin and incubated at $37^{\circ} \mathrm{C}$ in an incubator containing a humidified atmosphere of $95 \%$ air and $5 \% \mathrm{CO}_{2}$ and propagated according to the protocol supplied by the American Type Culture Collection.

Construction of the recombinant plasmids and transfection. The p-EGFP-N1 plasmid was kindly provided by Professor Haisheng Zhou (College of Biological Science, Anhui Medical University, China). The full-length wild-type PTEN mRNA was extracted from human lymphocytes, followed by amplification of PTEN cDNA with reverse transcription. PTEN cDNA was purified and cloned into pEGFP-N1 to construct the pEGFP-N1-PTEN (GFP-PTEN) plasmid. The pEGFP-N1 free vector was used as the control. U2-OS cells $\left(5 \times 10^{5}\right)$ were transiently transfected with $4 \mu \mathrm{g}$ plasmid DNA using Lipofectamine 2000, according to the manufacturer's protocol (Invitrogen Life Technologies, USA).
Cell adhesion assay. Cell adhesion assay was performed according to a previously reported method (35). Briefly, 24-well plates were coated with $10 \mu \mathrm{g} / \mathrm{ml}$ of rat tail type I collagen. The wells were blocked with $1 \%$ bovine serum albumin (BSA), and then $1 \times 10^{4}$ cells in $0.1 \%$ BSA were added into the wells in triplicate. After $20 \mathrm{~min}$, the wells were washed to remove unattached cells and were fixed with formalin. The cells were stained with $1 \%$ methylene blue in $0.01 \mathrm{M}$ borate buffer (pH 8.5), and were washed with distilled water. The numbers of adhesive cells were counted in 10 randomly selected fields (x100). The adhesive rate of the cells was calculated as the number of adhesive cells/the number of seeded cells. The adhesive curve was generated by plotting the adhesive rates of the different cells at each time point.

In vitro scratch assay. Cell migration was assessed using a scratch assay in vitro as previously described (36). U2-OS cells were added into 6-well plates and allowed to attach onto the plate with complete media with $10 \%$ fetal calf serum (FCS). Cells were washed with serum-free media and transfected with GFP or the GFP-PTEN plasmid. After a 20-h transfection, the monolayer of cells was wounded with a $10-\mu 1$ micropipette tip forming a scratch. The solution of debris was removed after washing with phosphate-buffered saline (PBS). Subsequently, those cells were cultured in fresh McCoy's 5A medium supplemented with $10 \%$ FBS. The baseline time of the scratch was determined (time of scratch, $0 \mathrm{~h}$ ). After $12 \mathrm{~h}$, the distance from one side of the scratch to the other side, into which the cells did not fill, was measured by Image Pro-Plus 6.0 software (Media Cybernetics, USA) in order to evaluate cell migration ability.

Cell invasion assay. The invasion assay in vitro was performed with a modified Boyden chamber consisting of a Transwell membrane filter inserted into 24-well culture plates. The Transwell filter was $6.5 \mathrm{~mm}$ in diameter, with a $8-\mu \mathrm{m}$ pore size covered with a $10-\mu \mathrm{m}$ thick polycarbonate membrane. The upper surface of the Transwell membrane was coated with $1 \mathrm{mg} / \mathrm{ml}$ Matrigel matrix overnight at $4^{\circ} \mathrm{C}$. The membrane was rehydrated with serum-free medium for $2 \mathrm{~h}$, and then placed into 24-well culture plates containing $600 \mu \mathrm{l}$ of invasion buffer per well. The invasion buffer was mixed with complete media and $10 \%$ FCS as an attractant. Cells were harvested using $0.53 \mathrm{mM}$ EDTA and resuspended in serum-free media and $0.1 \%$ BSA. Cells $\left(2 \times 10^{5}\right)$ suspended in $200 \mu 1$ of invasion buffer were added to each Transwell chamber and allowed to invade toward the underside of the membrane for $12 \mathrm{~h}$ at $37^{\circ} \mathrm{C}$. Non-invading cells were removed from the upper chamber by moist cotton tipped swabs, and the invaded cells were fixed by anhydrous alcohol for $15 \mathrm{~min}$ and stained with eosin for $5 \mathrm{~min}$. The number of invaded cells was counted in 5 randomly selected fields/membrane.

RNA purification. Cells were lysed by TRIzol reagent, and RNA was extracted according to the manufacturer's instructions (Sangon, China). In order to avoid genomic DNA contamination, extracted RNA was then purified with the RNeasy kit (Invitrogen). The quantity and quality of RNA were determined by the OD measurement at 260 and $280 \mathrm{~nm}$. The integrity of RNA was checked by visual inspection of the two rRNAs $28 \mathrm{~S}$ and $18 \mathrm{~S}$ on an agarose gel. 

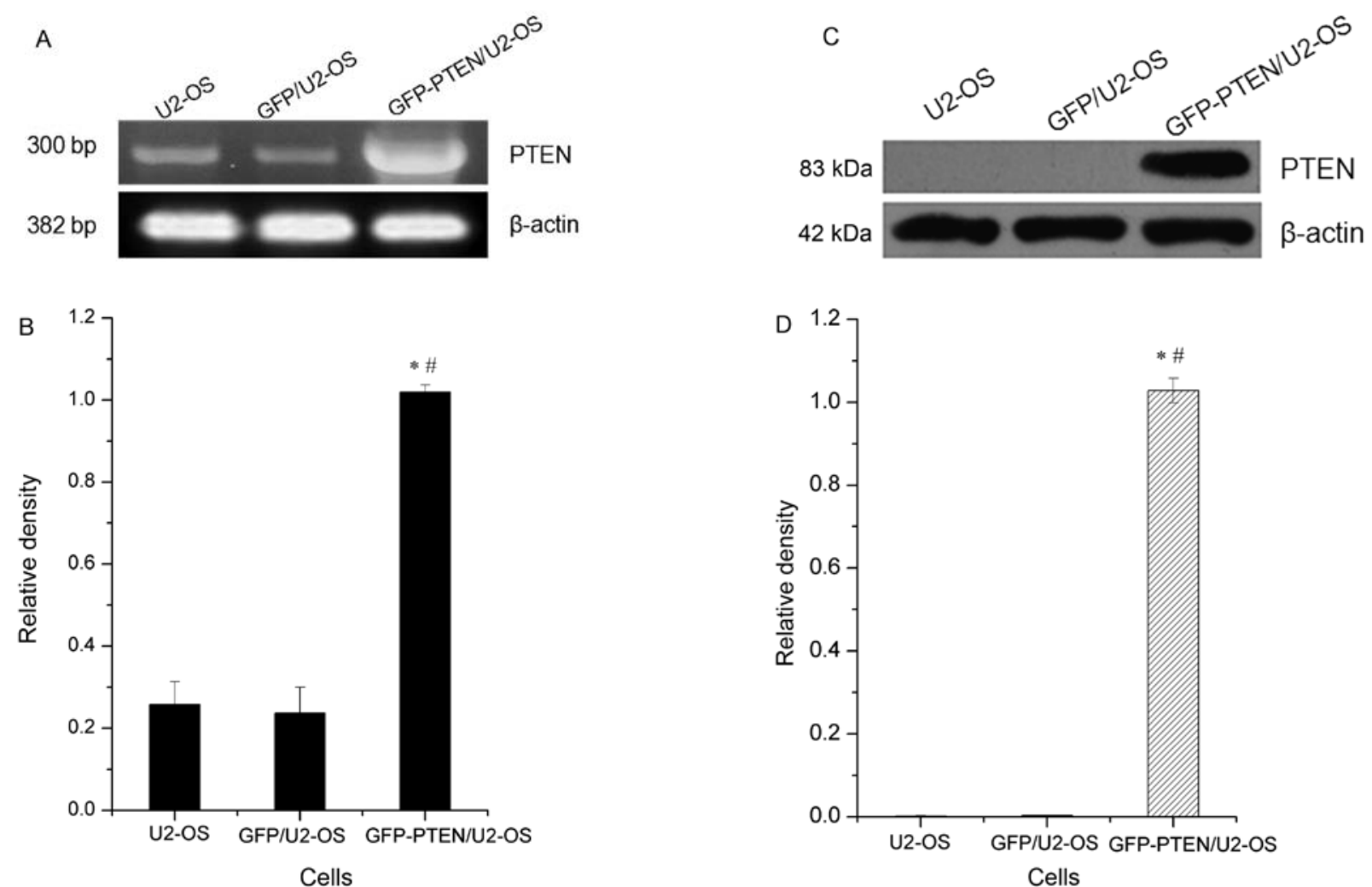

Figure 1. Changes in PTEN expression in osteosarcoma cells. (A and C) Expression of PTEN by RT-PCR and western blot analysis. (B and D) Quantitative analysis of the levels of PTEN mRNA and protein expression in the different cells, respectively. Similar results were obtained from three independent experiments. " $\mathrm{P}<0.01$ compared to control; ${ }^{*} \mathrm{P}<0.01$ compared to U2-OS cells with free plasmid. PTEN, phosphatase and tensin homolog; OS, osteosarcoma.

Reverse transcription-PCR. Two micrograms of RNA was used for cDNA synthesis using oligo $(\mathrm{dt})_{18}$ as primer and AMV reverse transcriptase. The RT reaction was started with a 10-min incubation at room temperature and $60 \mathrm{~min}$ at $42^{\circ} \mathrm{C}$ followed by $10 \mathrm{~min}$ at $70^{\circ} \mathrm{C}$ to terminate the reaction. Subsequently, $2 \mu \mathrm{l}$ of cDNA was used as a template to amplify the target genes by PCR in a total volume of $25 \mu 1$ containing $2.5 \mu 1$ 10X PCR buffer (0.2 M Tris-HCl, $\mathrm{pH} 8.4,0.5 \mathrm{M} \mathrm{KCl})$, $0.2 \mathrm{mM}$ dNTP mix, $1.5 \mathrm{mM} \mathrm{MgCl}_{2}, 0.2 \mu \mathrm{M}$ of each primer and 1.25 units of Platinum Taq DNA polymerase (Invitrogen). The thermal cycler was set to run at $95^{\circ} \mathrm{C}$ for $5 \mathrm{~min}, 30$ cycles at $94^{\circ} \mathrm{C}$ for $30 \mathrm{sec}, 60^{\circ} \mathrm{C}$ for $30 \mathrm{sec}, 72^{\circ} \mathrm{C}$ for $1 \mathrm{~min}$, and a final extension at $72^{\circ} \mathrm{C}$ for $10 \mathrm{~min}$. The specific primers for PTEN (upstream, 5'-AGTTCCCTCAGCCGTTACCT-3' and downstream, 5'-ATTTGACGGCTCCTCAACTG-3'; 300-bp fragment) were used. PCR products were analyzed by electrophoresis on $1.2 \%$ agarose gel. The specific bands were observed with ethidium bromide and digitally photographed under ultraviolet light, and further scanned using Gel Documentation System 920 (Nucleo Tech, San Mateo, CA, USA). Gene expression was calculated as the ratio of the mean band density of the specific product to that of the internal standard ( $\beta$-actin).

Western blot analysis. The cells following different treatments were scraped off from the culture flasks and lysed in lysis buffer containing $10 \%$ glycerol, $10 \mathrm{mM}$ Tris- $\mathrm{HCl}(\mathrm{pH} 6.8), 1 \%$ SDS, $5 \mathrm{mM}$ dithiothreitol (DTT) and 1X complete protease inhibitor cocktail (Sigma, USA). The method of Bradford was used to assay the concentrations of protein in the diverse samples. The protein concentration was measured using an auto multifunction microplate reader. Fifty micrograms of the proteins was separated by $8 \%$ polyacrylamide-SDS in consecutive gel electrophoresis. The separated proteins were electrophoretically transferred to polyvinylidene difluoride membranes. The membranes were blocked with $5 \%$ skim milk in Tris-buffered saline (TBS) containing $0.1 \%$ Tween-20 at room temperature for $1 \mathrm{~h}$ and then incubated each with the PTEN antibody (1:250 dilution), FAK antibody (1:500 dilution), p-FAK antibody (1:500 dilution), MMP-2 antibody (1:200 dilution) and MMP-9 antibody (1:200 dilution) overnight at $4^{\circ} \mathrm{C}$, followed by the secondary anti-rabbit IgG for $1 \mathrm{~h}$ at room temperature. Signals were detected with enhanced chemiluminescence (ECL Plus; Amersham, USA). $\beta$-actin protein at a 1:1,000 dilution was used as the internal control to observe changes in the different protein bands.

Statistical analysis. The results are shown as means \pm standard deviation (SD). The Student's t-test was used to compare results between groups using StatView software (SAS Institute Inc., Cary, NC, USA). The two-tailed p-value of $<0.05$ was considered to indicate a statistically significant result.

\section{Results}

Expression of PTEN in the OS cells after transfection. As shown in Fig. 1A and B, a higher level of PTEN transcriptional expression was displayed in the GFP-PTEN/U2-OS 


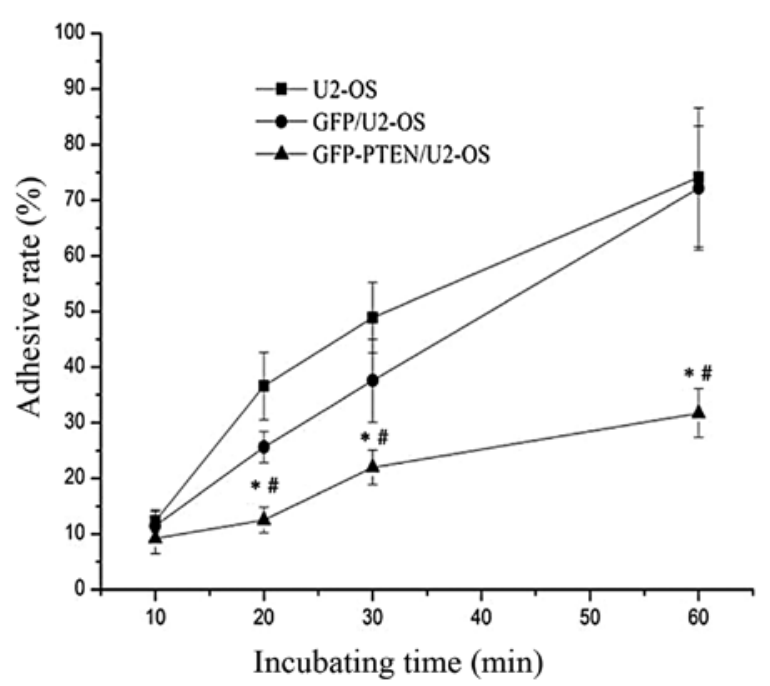

Figure 2. Changes in osteosarcoma cell adhesion. ${ }^{*} \mathrm{P}<0.01$ compared with the control; ${ }^{\prime} \mathrm{P}<0.01$ compared with the U2-OS cells with free plasmid. OS, osteosarcoma.

cells transfected with wild-type PTEN compared to these levels in the control and the U2-OS cells with free plasmid transfection. The results from the western blot assay further showed that high expression of PTEN protein was found in the GFP-PTEN/U2 cells (Fig. 1C and D).

Influence of PTEN expression on adhesion of OS cells. As one of the most important characteristics of tumors, the adhesion capability of OS cells was observed at different times. After U2-OS cells were transfected with the GFP-PTEN plasmid, there was a reduction in adhesion by $12.51 \pm 2.28,21.95 \pm 3.12$ and $31.73 \pm 4.36 \%$ at 20,30 and $60 \mathrm{~min}$, respectively, compared with the control and U2-OS cells with free plasmid. Although the adhesion rate of the U2-OS cells with free plasmid was lower than that of the control at $20 \mathrm{~min}$, the difference between the two cells gradually disappeared concomitant with time extension. The result from the statistical analysis is shown in Fig. 2.

Influence of PTEN on the migration and invasion of OS cells. We further determined the alteration in the distance of cells migrating through a scratch region to evaluate the migration and invasion capabilities of the different cells. The distance of GFP-PTEN/U2-OS cell migration was shorter than that of the control and GFP/U2-OS cells. Moreover, there was no statistical difference between the migration distances of the U2-OS and GFP/U2-OS cells (Fig. 3A and B). Upon determination of OS cell invasion, the average number of U2-OS, GFP/U2-OS
A

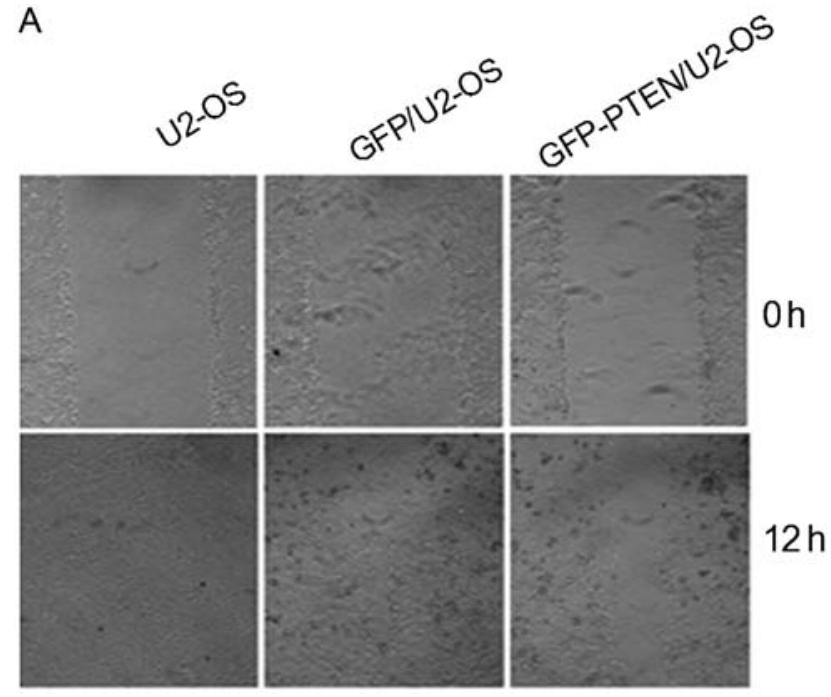

C

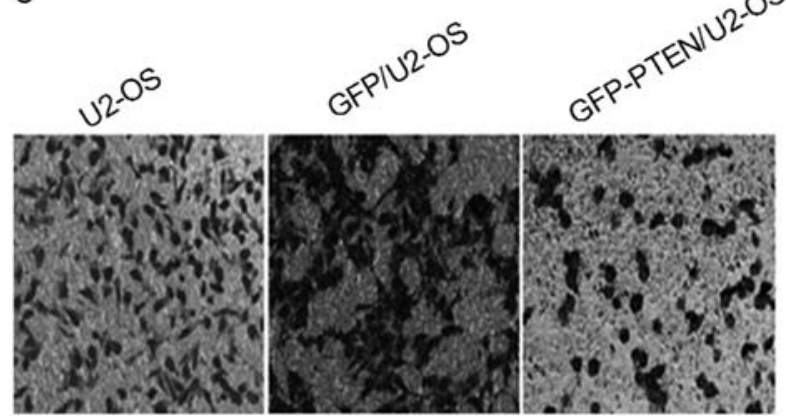

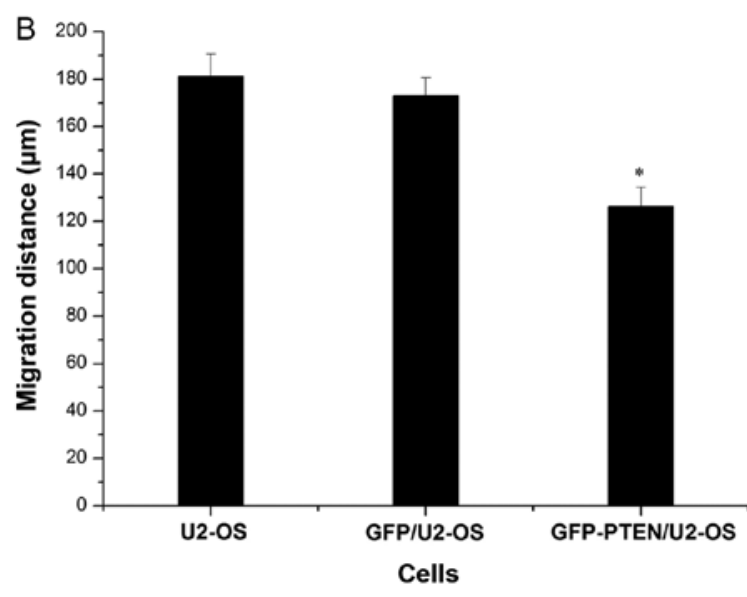

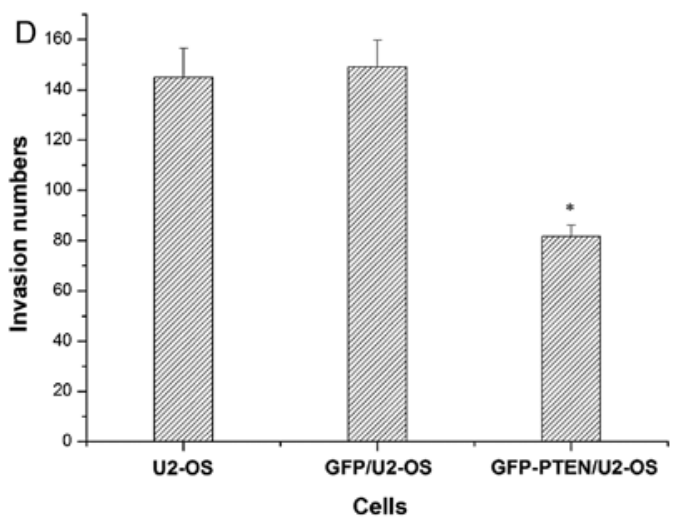

Figure 3. Changes in osteosarcoma cell migration and invasion. (A) Images of the confluent monolayers of U2-OS cells that were wounded. Images were captured initially $(\mathrm{t}=0 \mathrm{~h})$ and $24 \mathrm{~h}$ after wounding $(\mathrm{t}=24 \mathrm{~h})$. (B) Quantification of the endothelial wound repair. The distance of cell migration into the wound area was measured in U2-OS cells $24 \mathrm{~h}$ after wounding. Values are means $\pm \mathrm{SD}$ from three independent experiments. ${ }^{*} \mathrm{P}<0.01$ compared with the control. (C) Images of the different cells that invaded through the Matrigel and filter. (D) Results of the quantitative analysis from at least 10 fields, and three independent experiments are shown. ${ }^{*} \mathrm{P}<0.01$ compared with the control. OS, osteosarcoma. 

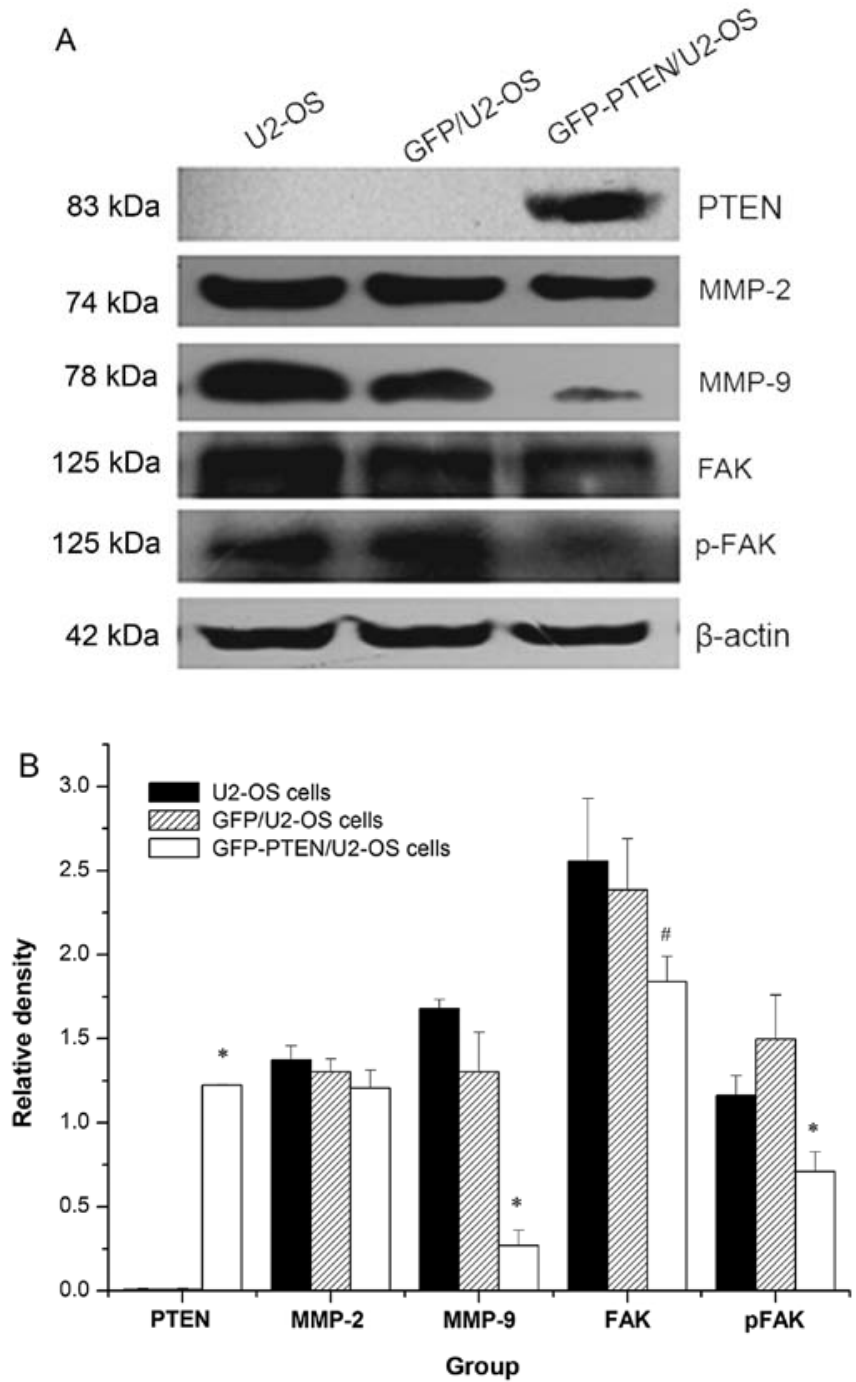

Figure 4. Changes in FAK and expression of its target genes. (A) Changes in the different proteins as assayed by western blot analysis. (B) Quantitative analysis of the levels of various proteins. Similar results were obtained from three independent experiments. ${ }^{\#} \mathrm{P}<0.01,{ }^{*} \mathrm{P}<0.01$ compared with the control. FAK, focal adhesion kinase.

and GFP-PTEN/U2-OS cells that invaded through the Matrigel and filter was $141 \pm 17,153 \pm 25$ and $84 \pm 7$, respectively (Fig. 3C and D). Therefore, there was a statistically significant reduction in the invasive and migratory abilities in the U2-OS cells following PTEN transfection.

Regulation by PTEN of the expression of FAK, MMP-2 and $M M P-9$. In regards to the mechanisms involved in the effects of PTEN on OS cells, the levels of FAK, MMP-2 and MMP-9 protein were subsequently observed. As shown in Fig. 4, high levels of the three proteins were noted in the U2-OS cells. Subsequently, high levels of FAK and MMP-2 were attenuated by PTEN transfection. Meanwhile, the phosphorylation of FAK was inhibited by the same transfection. Although a slight reduction in MMP-2 expression was observed in the GFP-PTEN/U2-OS cells, the alteration did not achieve statistical significance. Therefore, the results indicate that PTEN obviously decreased the level of MMP-9 and the expression and phosphorylation of FAK in the OS cells.

\section{Discussion}

Osteosarcoma (OS) is a serious disease affecting mainly children and young adults, and is characterized by very high metastatic capability (1). Although modern, multi-agent, dose-intensive chemotherapy in conjunction with surgery achieves a 5-year event-free survival of $60-70 \%$ in extremity localized, non-metastatic disease (37), OS-related morbidity and mortality remain high (2). Similar to other malignant tumors, early progression to metastatic disease is one of the main causes of treatment failure for OS (1). Previous studies have reported that inactivation of tumor-suppressor genes or the activation of oncogenes are important events in the genesis and development of tumors $(11,17,18,38)$. Growing evidence suggests that PTEN regulates a multitude of biological aggressive tumor behaviors, such as rapid growth, self-renewal and metastasis $(7,8,17,39,40)$. A low level of PTEN expression was detected in advanced diseases including glioma, pancreatic tumors, hepatocellular carcinoma, breast and prostate tumors (41-43). A large body of data show that increased PTEN expression inhibits the adhesion and metastatic capabilities of tumor cells via regulating FAK expression and phosphorylation $(25,27)$. In the present study, the OS cells with PTEN transfection showed decreased adhesion, migration and invasion compared to the cells with absence of PTEN expression, similar to the findings of previous studies on other tumors.

We further observed changes in the expression and phosphorylation of FAK due to the downstream genes of PTEN. Our results revealed that the expression of FAK was obviously decreased in OS cells after PTEN transfection. The phosphorylation of FAK was inhibited coinciding with the tendency of the elevation of PTEN expression. In adult tissues, FAK levels can be elevated during wound healing and transformation processes (44). Much data demonstrate that, although the levels of FAK mRNA in normal tissues are low, the overexpression and hyperphosphorylation of FAK are associated with many types of solid tumors $(45,46)$. Hyperactivity of FAK can promote survival and motility, contributing to tumorigenicity and metastasis. For example, the levels of FAK expression are low in normal colon or benign breast epithelium but high in biopsies derived from patients with colon and metastatic breast cancer $(47,48)$. According to previous data, FAK overexpression and phosphorylation are associated with esophageal adenocarcinoma, prostate carcinoma, gastric cancer recurrence, squamous cell carcinoma, progression of hepatocellular carcinoma, thyroid cancer, small cell lung carcinoma and oral tumor cell invasion (45-49).

In cancer cells, FAK has been shown to regulate cell migration and invasion through distinct pathways by promoting the dynamic regulation of focal adhesion and peripheral actin structures, as well as MMP-mediated matrix degradation (30-32,50). MMPs are major hydrolytic enzymes targeting ECM during metastasis and there is a clear connection between MMPs, ECM degradation and cancer cell invasion $(32,51)$. According to a previous study, MMP-9 was involved in the degradation of matrix components and thus supported the invasion and migration of tumor cells through the extracellular matrix (ECM) barriers (52). In our experiment, MMP-9 protein was at a lower level in the U2-OS cells transfected by the PTEN gene consistent with the finding of 
FAK expression and phosphorylation. Notably, the significant alteration of MMP-2 protein, another matrix metalloproteinase of the MMP family, was not noted in our experiment similar to recent studies $(32,53)$. According to the results of Matsumoto et al (54), the regulation of MMP-2 is influenced by the Rho-ROCK pathway, but not FAK, in OS cells. It was thus demonstrated that the migration and invasion capabilities of U2-OS cells with PTEN expression were decreased via the blockage of FAK/MMP signaling.

Collectively, our experimental results suggest that increased level of the PTEN gene may significantly decrease the adhesion, migration and invasion abilities of OS cells, involving the blockage of FAK/MMP9 signaling. PTEN is therefore valuable for the prognosis and the design of new targeting therapies for OS.

\section{Acknowledgements}

We thank Haisheng Zhou for the p-EGFP-N1 plasmid, and the Shanghai Cell Bank of Chinese Academy of Sciences for the U2-OS cells. The present study was supported by the National Natural Science Foundation of China (no. 81173075).

\section{References}

1. Yui Y, Itoh K, Yoshioka K, et al: Mesenchymal mode of migration participates in pulmonary metastasis of mouse osteosarcoma LM8. Clin Exp Metastasis 27: 619-630, 2010.

2. Bianchi E, Artico M, Di Cristofano C, et al: Growth factors, their receptor expression and markers for proliferation of endothelial and neoplastic cells in human osteosarcoma. Int J Immunopatho Pharmacol 26: 621-632, 2013.

3. Rainusso N, Wang LL and Yustein JT: The adolescent and young adult with cancer: state of the art - bone tumors. Curr Oncol Rep 15: 296-307, 2013.

4. Fayda M, Kebudi R, Dizdar Y, Gorgun O, Gun F, Aksu G and Ayan I: Spontaneous pneumothorax in children with osteosarcoma: report of three cases and review of the literature. Acta Chir Belg 112: 378-381, 2012.

5. Ritter J and Bielack SS: Osteosarcoma. Ann Oncol 21: vii320-vii325, 2010.

6. Bacci G, Longhi A, Versari M, Mercuri M, Briccoli A and Picci P: Prognostic factors for osteosarcoma of the extremity treated with neoadjuvant chemotherapy: 15-year experience in 789 patients treated at a single institution. Cancer 106: 1154-1161, 2006.

7. Li Z, Liao Q, Wu Y, et al: Upregulation of a disintegrin and metalloprotease 8 influences tumor metastasis and prognosis in patients with osteosarcoma. Pathol Oncol Res 18: 657-661, 2012.

8. Sarkar S, Dubaybo H, Ali S, et al: Down-regulation of miR-221 inhibits proliferation of pancreatic cancer cells through up-regulation of PTEN, p27 ${ }^{\mathrm{kip} 1}$, p57 $7^{\mathrm{kip} 2}$, and PUMA. Am J Cancer Res 3: 465-477, 2013.

9. Sekine S, Shimada Y, Nagata T, et al: Role of aquaporin-5 in gallbladder carcinoma. Eur Surg Res 51: 108-117, 2013.

10. Li Y, Guessous F, DiPierro C, et al: Interactions between PTEN and the c-Met pathway in glioblastoma and implications for therapy. Mol Cancer Ther 8: 376-385, 2009.

11. Schneider E, Keppler R, Prawitt D, et al: Migration of renal tumor cells depends on dephosphorylation of She by PTEN. Int J Oncol 38: 823-831, 2011.

12. Shukla S, Pia Patric IR, Thinagararjan S, et al: A DNA methylation prognostic signature of glioblastoma: identification of NPTX2-PTEN-NF-kB nexus. Cancer Res 73: 6563-6573, 2013.

13. Rogers HA, Mayne C, Chapman RJ, Kilday JP, Coyle B and Grundy RG: PI3K pathway activation provides a novel therapeutic target for pediatric ependymoma and is an independent marker of progression-free survival. Clin Cancer Res 19: 6450-6460, 2013.

14. Colangelo T, Fucci A, Votino C, et al: MicroRNA-130b promotes tumor development and is associated with poor prognosis in colorectal cancer. Neoplasia 15: 1218-1231, 2013.
15. Aoyama D, Hashimoto N, Sakamoto K, et al: Involvement of TGF $\beta$-induced phosphorylation of the PTEN C-terminus on TGF $\beta$-induced acquisition of malignant phenotypes in lung cancer cells. PLoS One 8: e81133, 2013.

16. Carver BS, Tran J, Gopalan A, et al: Aberrant ERG expression cooperates with loss of PTEN to promote cancer progression in the prostate. Nat Genet 41: 619-624, 2009.

17. Dey N, Crosswell HE, De P, Parsons R, Peng Q, Su JD and Durden DL: The protein phosphatase activity of PTEN regulates SRC family kinases and controls glioma migration. Cancer Res 68: 1862-1871, 2008.

18. Sze KM, Wong KL, Chu GK, Lee JM, Yau TO and Ng IO: Loss of phosphatase and tensin homolog enhances cell invasion and migration through AKT/Sp-1 transcription factor/matrix metalloproteinase 2 activation in hepatocellular carcinoma and has clinicopathologic significance. Hepatology 53: 1558-1569, 2011.

19. Marsh Durban V, Jansen M,Davies EJ, Morsink FH, Offerhaus GJ and Clarke AR: Epithelial-specific loss of PTEN results in colorectal juvenile polyp formation and invasive cancer. Am J Pathol 184: 86-91, 2014.

20. Metcalfe C, Alicke B, Crow A, et al: PTEN loss mitigates the response of medulloblastoma to Hedgehog pathway inhibition. Cancer Res 73: 7034-7042, 2013.

21. Garcia-Carracedo D, Turk AT, Fine SA, et al: Loss of PTEN expression is associated with poor prognosis in patients with intraductal papillary mucinous neoplasms of the pancreas. Clin Cancer Res 19: 6830-6841, 2013.

22. Leinonen KA, Saramäki OR, Furusato B, et al: Loss of PTEN is associated with aggressive behavior in ERG-positive prostate cancer. Cancer Epidemiol Biomarkers Prev 22: 2333-2344, 2013.

23. Matsuda S, Nakanishi A, Wada Y and Kitagishi Y: Roles of PI3K/ AKT/PTEN pathway as a target for pharmaceutical therapy. Open Med Chem J 7: 23-29, 2013.

24. Germani A, Matrone A, Grossi V, et al: Targeted therapy against chemoresistant colorectal cancers: inhibition of $\mathrm{p} 38 \alpha$ modulates the effect of cisplatin in vitro and in vivo through the tumor suppressor $\mathrm{FoxO}_{3} \mathrm{~A}$. Cancer Lett 344: 110-118, 2013.

25. Tamura M, Gu J, Takino T and Yamada KM: Tumor suppressor PTEN inhibition of cell invasion, migration, and growth: differential involvement of focal adhesion kinase and p130 Cas. Cancer Res 59: 442-449, 1999.

26. Alimonti A, Carracedo A, Clohessy JG, et al: Subtle variations in Pten dose determine cancer susceptibility. Nat Genet 42: 454-458, 2010.

27. Gu J, Tamura M, Pankov R, Danen EH, Takino T, Matsumoto K and Yamada KM: Shc and FAK differentially regulate cell motility and directionality modulated by PTEN. J Cell Biol 146: 389-403, 1999.

28. Crompton BD, Carlton AL, Thorner AR, et al: High-throughput tyrosine kinase activity profiling identifies FAK as a candidate therapeutic target in Ewing sarcoma. Cancer Res 73: 2873-2883, 2013.

29. Caino MC, Chae YC, Vaira V, et al: Metabolic stress regulates cytoskeletal dynamics and metastasis of cancer cells. J Clin Invest 123: 2907-2920, 2013.

30. Castillo-Sanchez R, Villegas-Comonfort S, GalindoHernandez O, Gomez R and Salazar EP: Benzo- $[a]-$ pyrene induces FAK activation and cell migration in MDA-MB-231 breast cancer cells. Cell Biol Toxicol 29: 303-319, 2013.

31. Kessenbrock K, Plaks V and Werb Z: Matrix metalloproteinases: regulators of the tumor microenvironment. Cell 141: 52-67, 2010.

32. Hanna SC, Krishnan B, Bailey ST, et al: HIF1 $\alpha$ and HIF2 $\alpha$ independently activate SRC to promote melanoma metastases. J Clin Invest 123: 2078-2093, 2013.

33. Miwa S, Sugimoto N, Yamamoto N, et al: Caffeine induces apoptosis of osteosarcoma cells by inhibiting AKT/mTOR/S6K, NF-кB and MAPK pathways. Anticancer Res 32: 3643-3649, 2012.

34. Namløs HM, Meza-Zepeda LA, Barøy T, et al: Modulation of the osteosarcoma expression phenotype by microRNAs. PLoS One 7: e48086, 2012.

35. Luo X, Sharff KA, Chen J, He TC and Luu HH: S100A6 expression and function in human osteosarcoma. Clin Orthop Relat Res 466: 2060-2070, 2008.

36. Cai C, Rodepeter FR, Rossmann A, et al: Nef from $\operatorname{SIV}_{\text {mac239 }}$ decreases proliferation and migration of adenoid-cystic carcinoma cells and inhibits angiogenesis. Oral Oncol 47: 847-854, 2011.

37. Luetke A, Meyers PA, Lewis I and Juergens H: Osteosarcoma treatment - where do we stand? A state of the art review. Cancer Treat Rev 40: 523-532, 2014. 
38. Muhlbradt E, Ma J, Severi G, et al: Variant NKX3.1 and serum IGF-1: investigation of interaction in prostate cancer. Genes Cancer 4: 535-545, 2013.

39. Davies EJ, Marsh Durban V, Meniel V, Williams GT and Clarke AR: PTEN loss and KRAS activation leads to the formation of serrated adenomas and metastatic carcinoma in the mouse intestine. J Pathol 233: 27-38, 2014.

40. Paul P, Qiao J, Kim KW, et al: Targeting gastrin-releasing peptide suppresses neuroblastoma progression via upregulation of PTEN signaling. PLoS One 8: e72570, 2013.

41. Song MS, Salmena L and Pandolfi PP: The functions and regulation of the PTEN tumour suppressor. Nat Rev Mol Cell Biol 13: 283-296, 2012.

42. Krausch M, Raffel A, Anlauf M, et al: Loss of PTEN expression in neuroendocrine pancreatic tumors. Horm Metab Res 43 : 865-871, 2011

43. Dasari VR, Kaur K, Velpula KK, et al: Upregulation of PTEN in glioma cells by cord blood mesenchymal stem cells inhibits migration via downregulation of the PI3K/Akt pathway. PLoS One 5: e10350, 2010.

44. Mierke CT: The role of focal adhesion kinase in the regulation of cellular mechanical properties. Phys Biol 10: 065005, 2013.

45. Ji HF, Pang D, Fu SB, Jin Y, Yao L, Qi JP and Bai J: Overexpression of focal adhesion kinase correlates with increased lymph node metastasis and poor prognosis in non-small-cell lung cancer. J Cancer Res Clin Oncol 139: 429-435, 2013.

46. Ko BS, Jan YJ, Chang TC, et al: Upregulation of focal adhesion kinase by $14-3-3 \varepsilon$ via $\mathrm{NF \kappa B}$ activation in hepatocellular carcinoma. Anticancer Agents Med Chem 13: 555-562, 2013.

47. Provenzano PP, Inman DR, Eliceiri KW, Beggs HE and Keely PJ: Mammary epithelial-specific disruption of focal adhesion kinase retards tumor formation and metastasis in a transgenic mouse model of human breast cancer. Am J Pathol 173: 1551-1565, 2008.
48. Baranwal S, Wang Y, Rathinam R, et al: Molecular characterization of the tumor-suppressive function of nischarin in breast cancer. J Natl Cancer Inst 103: 1513-1528, 2011.

49. Golubovskaya VM and Cance W: Focal adhesion kinase and p53 signal transduction pathways in cancer. Front Biosci 15: 901-912, 2010.

50. Shih YW, Chien ST, Chen PS, Lee JH, Wu SH and Yin LT: $\alpha$-mangostin suppresses phorbol 12-myristate 13-acetate-induced MMP-2/MMP-9 expressions via $\alpha v \beta 3$ integrin/FAK/ERK and NF- $\kappa$ B signaling pathway in human lung adenocarcinoma A549 cells. Cell Biochem Biophys 58: 31-44, 2010.

51. Pal S, Ganguly KK and Chatterjee A: Extracellular matrix protein fibronectin induces matrix metalloproteinases in human prostate adenocarcinoma cells PC-3. Cell Commun Adhes 20: 105-114, 2013.

52. Poudel B, Kim DK, Ki HH, Kwon YB, Lee YM and Kim DK: Downregulation of ERK signaling impairs U2OS osteosarcoma cell migration in collagen matrix by suppressing MMP9 production. Oncol Lett 7: 215-218, 2014.

53. Lu XS, Sun W, Ge CY, Zhang WZ and Fan YZ: Contribution of the PI3K/MMPs/Ln-5 $\gamma 2$ and EphA2/FAK/Paxillin signaling pathways to tumor growth and vasculogenic mimicry of gallbladder carcinomas. Int J Oncol 42: 2103-2115, 2013.

54. Matsumoto Y, Tanaka K, Harimaya K, Nakatani F, Matsuda S and Iwamoto Y: Small GTP-binding protein, Rho, both increased and decreased cellular motility, activation of matrix metalloproteinase 2 and invasion of human osteosarcoma cells. Jpn J Cancer Res 92: 429-438, 2001. 